\title{
ANALISIS PERPECAHAN KEPEMIMPINAN ANTARGENERASI DI LINGKUNGAN GEREJA
}

\section{Djone Georges Nicolas}

Sekolah Tinggi Teologi (STT) IKAT Jakarta, Indonesia

Email: djonealexandrenathanael@gmail.com

\begin{abstract}
The purpose of this paper is to find out why there are divisions and gaps in intergenerational leadership in the church environment and how to overcome them. The concept that underlies today's erroneous intergenerational leadership is the cause of divisions and gaps in church leadership in Indonesia. Millennial generation leaders feel that they are not being considered, given the opportunity and neglected by their capacity to lead, so they do not feel part of the goals the church is trying to achieve. This research uses descriptive qualitative research, with a literature analysis method approach and narrative interpretation, by collecting data through biblical sources, books, journals, digital articles, interviews and other documents related to the issues being studied. First, intergenerational leadership is seen as regeneration or taking turns, like a career path where seniority is a priority criterion. Second, there is no interaction between generations. In conclusion, it is necessary to have a correct understanding of intergenerational leadership in church organizations so that intergenerational leadership becomes a culture, so that not only trust arises, but also intergenerational cooperation and not division.
\end{abstract}

Keywords: divisions; leadership; intergenerational; church; Indonesia

\begin{abstract}
Abstrak
Tujuan penulisan ini adalah hendak mengetahui mengapa terjadi perpecahan maupun gap dalam kepemimpinan antargenerasi di lingkungan gereja dan bagaimana cara mengatasinya. Konsep yang mendasari kepemimpinan antargenerasi yang keliru hari ini menjadi penyebab terjadinya perpecahan dan gap dalam kepemimpinan gereja di Indonesia. Pemimpin generasi millenial mempunyai perasaan tidak dianggap, tidak diberi kesempatan dan diabaikan kapasitas mereka dalam memimpin, sehingga tidak merasa menjadi bagian dalam tujuan yang hendak dicapai gereja. Penelitian ini menggunakan penelitian kualitatif deskriptif, dengan pendekatan metode analisis pustaka dan tafsir narasi, dengan pengumpulan data melalui sumber Alkitab, buku-buku, jurnal-jurnal, artikel digital, wawancara dan dokumen lain yang berkaitan dengan masalah yang dikaji. Pertama, kepemimpinan antargenerasi dipandang sebagai regenerasi atau bergiliran, seperti perjalanan karir di mana senioritas menjadi kriteria prioritas. Kedua, Tidak terdapat interaksi yang ideal antar generasi. Kesimpulan, diperlukan pemahaman yang benar tentang kepemimpinan antargenerasi di dalam organisasi gereja agar kepemimpinan
\end{abstract}

\begin{tabular}{ll}
\hline How to cite: & Nicolas, Djone George (2021) Analisis Perpecahan Kepemimpinan Antargenerasi Di Lingkungan \\
& Gereja. Syntax Literate. 6(5). http://dx.doi.org/10.36418/syntax-literate.v6i5.2686 \\
E-ISSN: & 2548-1398 \\
Published by: & Ridwan Institute
\end{tabular}

Published by: $\quad$ Ridwan Institute 
antargenerasi menjadi suatu budaya, sehingga bukan sekedar timbul kepercayaan, tetapi juga kerja sama antargerenasi dan bukan perpecahan.

Kata Kunci: perpecahan; kepemimpinan; antargenerasi; gereja; Indonesia

\section{Pendahuluan}

Kepemimpinan merupakan suatu kebutuhan dalam perjalanan satu organisasi, sebab kepemimpinan sangat mempengaruhi keputusan dan kebijakan yang menentukan arahnya organisasi tersebut, termasuk di dalam gereja. Fakta bahwa tidak ada kepemimpinan yang abadi di dunia ini, memberi kesadaran bahwa kepemimpinan antargenerasi perlu menjadi prioritas dalam gereja Tuhan demi pencapaian yang maximal, yang seturut dengan Amanat Agung Tuhan Yesus Kristus.

Menurut (Norrod, 2020), di Komunitas NPC di Tenesse, yang menjadi penyebab utama perpecahan antargenerasi adalah penolakan kegiatan yang sekuler seperti pendidikan maupun teknologi, dikarenakan pemimpin yang lebih senior tidak menerima pemimpin milenial yang memeluk teknologi. Salah satu persoalan dalam kepemimpinan antargenerasi dalam penulisan (Schlesman, 2020) adalah bahwa pemimpinan yang lebih tua ragu memberi kepercayaan kepada mereka yang lebih muda untuk melanjutkan kepemimpinan gereja, disebabkan mereka tidak yakin nilai dan kegiatan yang sudah ada akan dipertahankan. (Julita Nafthalia Leander, 2019) dalam tesisnya menyampaikan bahwa generasi yang kompleks sering menjadi penyebab setiap orang dari generasi yang berlainan kecenderung bersaing dalam hal penggunaan tempat, jam kegiatan dan juga perebutan sumber daya yang terdapat di dalam lingkungan gereja. Menurut (Douglas, 2013), gereja lokal dan hubungan yang terjalin di dalam gereja antara hamba Tuhan yang lebih tua dengan yang lebih muda akan memberi kesempatan untuk mewariskan kepemimpinan yang stabil. Oleh sebab itu gembala sebagai pemimpin dituntut memakai cara-cara yang akurat untuk membuat pilihan di antara jemaat dari beberapa orang yang hendak dijadikan pemimpin mengganti dirinya sebagai pemimpin rohani masa kini (Kassi Henos, Ervi Johan Lo, Sabar Manahan Hutagalung, 2018).

Menurut data Bambang Budijanto pada Minggu 28 Februari 2021 melalui acara webinar Zoom Now and Next Movement, terdapat enam generasi angkatan secara sosiologis dengan ciri khas masing-masing: Traditionalist kelahiran sebelum 1946 (Hard working, consistency, will power, respect and loyal), Baby Boomers kelahiran 1946-1961 (Competitive, legacy, experience), GEN X kelahiran 1961-1981 (Adaptive life and work balance, educational, skills, speed), GEN Y kelahiran 1981-1996 (Multitasker and networking, look out of the box, transparency), GEN Z kelahiran 1996-2011 (Digitaly savvy, super optimistic about the world, purpose), dan GEN A kelahiran setelah 2011. 
Tabel 1

Perbandingan Karakter dan Peristiwa Penting antargenerasi

GENERASI

\begin{tabular}{|c|c|c|c|c|}
\hline & VETERAN & BB & GEN X & GEN Y \\
\hline Periode & $1925-1944$ & 1945-1964 & $1965-1981$ & $1982-2000$ \\
\hline Istilah & $\begin{array}{l}\text { Tradisional, } \\
\text { mature, silent } \\
\text { generation }\end{array}$ & Boomers & $\begin{array}{l}\text { Post-Boomers } \\
\text { Baby Buster }\end{array}$ & $\begin{array}{l}\text { Millenials; } \\
\text { Nexter }\end{array}$ \\
\hline Peristiwa Utama & $\begin{array}{ll}\text { Depresi } & \text { besar; } \\
\text { perang } & \text { dunia } \\
\text { kedua } & \\
\end{array}$ & $\begin{array}{l}\text { Perang dingin; } \\
\text { Kemakmuran }\end{array}$ & $\begin{array}{ll}\text { Hak } & \text { asasi } \\
\text { manusia; } & \\
\text { persamaan } & \text { hak } \\
\text { wanita } & \\
\end{array}$ & $\begin{array}{l}\text { Perang Irak dan } \\
\text { teluk, jatuhnya } \\
\text { komunis; } \\
\text { revolusi internet }\end{array}$ \\
\hline Ciri di dunia kerja & $\begin{array}{l}\text { Etos kerja tinggi; } \\
\text { Respek } \\
\text { menghargai } \\
\text { otoritas }\end{array}$ & $\begin{array}{l}\text { Berorientensi } \\
\text { tim, optimis, } \\
\text { loyal, pekerja } \\
\text { keras }\end{array}$ & $\begin{array}{l}\text { Praktism } \\
\text { pesemis;mengejar } \\
\text { kesimbangan } \\
\text { hidup, } \\
\text { independent, } \\
\text { cepat beradaptasi }\end{array}$ & $\begin{array}{l}\text { Ambisius, multi- } \\
\text { tasking, percaya } \\
\text { diri, independent }\end{array}$ \\
\hline $\begin{array}{l}\text { Gaya } \\
\text { Kepeminpinan }\end{array}$ & $\begin{array}{l}\text { Militer, Rantai } \\
\text { komando }\end{array}$ & $\begin{array}{l}\text { Mau } \\
\text { mempengaruhi, } \\
\text { monitoring }\end{array}$ & $\begin{array}{l}\text { Praktis, } \\
\text { berorientensi } \\
\text { tujuan }\end{array}$ & Fleksibel \\
\hline Motivasi & $\begin{array}{l}\text { Penghargaan atas } \\
\text { pengalaman, } \\
\text { ketekunan, } \\
\text { kestiaan }\end{array}$ & $\begin{array}{l}\text { Kemampuan, } \\
\text { bonus, insentif, } \\
\text { kontribusi }\end{array}$ & Insentif liburan & $\begin{array}{l}\text { Jabatan, uang, } \\
\text { kebutuhan, } \\
\text { persetujuan, } \\
\text { sosial rendah }\end{array}$ \\
\hline
\end{tabular}

Gaya belajar Ruang kelas, on
the job training

Ruang kelas, Penggunaan penggunaan, teknologi, Berfikir kreatif, instruktur mentor

Sumber: (Adiawaty, 2019)

Tabel 2

Generational behavioural characteristics of different age-groups

\begin{tabular}{|c|c|c|c|c|}
\hline Factors & Baby - boom & X Generation & Y Generation & Z Generation \\
\hline View & $\begin{array}{l}\text { Communal, } \\
\text { unified thinking }\end{array}$ & $\begin{array}{l}\text { Self-centred and } \\
\text { medium-term }\end{array}$ & $\begin{array}{l}\text { Egotistical, } \\
\text { short term }\end{array}$ & $\begin{array}{l}\text { No sense of } \\
\text { commitment, be } \\
\text { happy with what } \\
\text { you have and live } \\
\text { for the present }\end{array}$ \\
\hline Relationship & $\begin{array}{l}\text { First and fore } \\
\text { most personal }\end{array}$ & $\begin{array}{l}\text { Personal and } \\
\text { virtual } \\
\text { networks }\end{array}$ & $\begin{array}{c}\text { Principally } \\
\text { virtual, network }\end{array}$ & $\begin{array}{l}\text { Virtual and } \\
\text { superficial }\end{array}$ \\
\hline Aim & Solid existence & $\begin{array}{l}\text { Multi-environ } \\
\text { ment, secure } \\
\text { position }\end{array}$ & $\begin{array}{l}\text { Rivalty for leader } \\
\text { position }\end{array}$ & $\begin{array}{l}\text { Live for the } \\
\text { present }\end{array}$ \\
\hline Self relaizations & $\begin{array}{l}\text { Conscious } \\
\text { carrier building }\end{array}$ & Rapid promotion & Immediate & $\begin{array}{l}\text { Questions the } \\
\text { need for it at all }\end{array}$ \\
\hline IT & $\begin{array}{l}\text { It is based on } \\
\text { self-instruction }\end{array}$ & $\begin{array}{l}\text { Uses with } \\
\text { confidence }\end{array}$ & $\begin{array}{l}\text { Part of its every } \\
\text { day life }\end{array}$ & Intuitive \\
\hline
\end{tabular}




\begin{tabular}{|c|c|c|c|c|}
\hline Factors & Baby - boom & X Generation & Y Generation & Z Generation \\
\hline & and incomplete & & & \\
\hline Values & $\begin{array}{l}\text { Patience, soft } \\
\text { skills, respect } \\
\text { for traditions, } \\
\text { EQ, hard work }\end{array}$ & $\begin{array}{l}\text { Hard work, open } \\
\text { ness, respect for } \\
\text { diversity, curios } \\
\text { ity, practicality }\end{array}$ & $\begin{array}{l}\text { Flexibility, } \\
\text { mobility, broad } \\
\text { but superficial } \\
\text { knowledge, } \\
\text { success orienta- } \\
\text { tion, creativity, } \\
\text { freedom of } \\
\text { Infor-mation } \\
\text { takes priority }\end{array}$ & $\begin{array}{l}\text { Live for the } \\
\text { present, rapid } \\
\text { reaction to eve } \\
\text { rything,initiator, } \\
\text { brave, rapid } \\
\text { information } \\
\text { access and } \\
\text { content search }\end{array}$ \\
\hline $\begin{array}{l}\text { Others possible } \\
\text { characteristics }\end{array}$ & $\begin{array}{l}\text { Respect for } \\
\text { hierarchy, exag } \\
\text { gerated mod } \\
\text { esty or arrogant } \\
\text { inflexibility, } \\
\text { passivity, cyni } \\
\text { cism, disap } \\
\text { pointment }\end{array}$ & $\begin{array}{l}\text { Rule abiding, } \\
\text { materialistic, fair } \\
\text { play, less respect } \\
\text { for hie- } \\
\text { rarchy, has a } \\
\text { sense of relati- } \\
\text { vity, need to } \\
\text { provethemselves }\end{array}$ & $\begin{array}{l}\text { Desire for } \\
\text { independence, } \\
\text { no respect for } \\
\text { tradition, quest } \\
\text { for new forms } \\
\text { of knowledge, } \\
\text { inverse socializa } \\
\text { tion, arrogant, } \\
\text { home office and } \\
\text { part-time work, } \\
\text { interim manage } \\
\text { ment,undervalue } \\
\text { soft skills and EQ }\end{array}$ & $\begin{array}{l}\text { Differing view } \\
\text { points, lack of } \\
\text { thinking, hap } \\
\text { piness, pleasure, } \\
\text { dividedattention, } \\
\text { lack of conse } \\
\text { quentialthinking, } \\
\text { no desire to } \\
\text { makesense of } \\
\text { things, the boun- } \\
\text { daries of work } \\
\text { and entertain- } \\
\text { ment overlap, } \\
\text { feel at home } \\
\text { anywhere }\end{array}$ \\
\hline
\end{tabular}

Sumber: (Bencsik \& Machova, 2016)

Data di atas menunjukkan kompleksitas perbedaan antargenerasi yang mau tidak mau dan suka tidak suka harus di hadapi oleh gereja, terlebih secara khusus dalam hal kepemimpinan. Perlu diakui bahwa gereja sebagai organisme dan juga sebagai organisasi, tidaklah mudah mewujudkan kepemimpinan antargenerasi, sebab di dalam gereja sebagai persekutuan atau komunitas terdapat generasi yang berbeda sehingga menjadi tantangan tersendiri bagi keberlangsungan kehidupan bergereja, oleh karena ketegangan sangat mungkin terjadi karena berbagai perbedaan seperti usia, cara pandang, selera, motivasi, budaya dan sebagainya. Gereja sebagai tubuh Kristus pada dasarnya adalah satu kesatuan di mana seharusnya kesatuan menjadi esensial, namum pada kenyataannya, gereja menghadapi gap antargenerasi yang menyebabkan terjadi kelompok-kelompok sesuai generasi masing-masing sehingga sering kali kelompok tertentu mendapat perhatian yang khusus, dan kelompok yang lain merasa diabaikan sehingga dapat menjadi sumber konflik di dalam gereja. Apabila hal ini tidak segera dijembatani, kemungkinan besar gereja dapat kehilangan beberapa generasi yang sesungguhnya merupakan aset dan masa depan gereja. Gereja membutuhkan semua generasi dalam menjalankan "Missio Dei". Oleh karenanya, penulis hendak mengetahui mengapa terjadi perpecahan maupun gap dalam kepemimpinan antargenerasi di lingkungan gereja dan bagaimana cara mengatasinya. 


\section{Metode Penelitian}

Penelitian ini menggunakan pendekatan kualitif dengan metode deskriptif dan analisa literatur maupun literatur research dengan tujuan menganalisa dengan tujuan hendak mengetahui mengapa terjadi perpecahan maupun gap dalam kepemimpinan antargenerasi di lingkungan gereja dan bagaimana mengatasinya. Untuk mencapai tujuan tersebut, teknik pengumpulan data melalui Alkitab, sumber buku-buku, artikel digital, jurna-jurnal, wawancara serta dokumen lain yang berkaitan dengan masalah yang menjadi objek kajian. Penelitian kualitatif menurut (Bogdan, 1992) merupakan prosedur penelitian yang menghasilkan tipe data deskriptif yang berupa ucapan atau tulisan dan perilaku orang-orang yang diamati di dalam suatu konteks dan yang dikaji dari sudut pandang yang lengkap dan komprehensif, maupun menyeluruh atau holistik. Deskriptif karena mempelajari masalah-masalah di tengah masyarakat serta pengaruhpengaruh dari suatu fenomena agar menjadi sebuah uraian yang mendalam. Analisa data dilakukan penulis dengan menemukan, mengumpulkan, serta mengkomparasikan secara kualitatif temuan-temuan yang diperoleh sebelum menarik sebuah kesimpulan.

\section{Hasil dan Pembahasan}

\section{A. Kepemimpinan Antargenerasi Dipandang Sebagai Regenerasi atau Bergiliran}

Generasi muda zaman sekarang belum siap untuk dipercayakan tanggung jawab memimpin, sehingga harus dibimbing sambil tunggu giliran mereka. Handy sebagai anak gembala menyatakan: "di gereja kami, setelah bapa (gembala) pensiun nanti, kakak saya yang akan melanjutkan kepemimpinan penggembalaan, dan setelah itu barulah saya" (Wawancara, 2021). Menurut Alex Sutanto kepemimpinan dalam gereja yang ideal hari ini apa bila tidak mau kehilangan gemerai anak-anak muda, adalah kalau para senior menyerahkan tongkat estafet kepada generasi berikut, sebab masa mereka sudah lewat dan ini masa millenial (Wawancara, 2021). Sehebat dan sebagus apa pun, pemimpin di dalam organisasi non rohani maupun rohani waktunya akan menyerahkan posisi kepemimpinan tersebut pada generasi berikutnya, yaitu generasi muda, dikarenakan ada batas usia untuk memimpin (Hahuluy, 2020). Ketiadaan kepemimpinan yang efisien dalam gereja dapat menyebabkan gereja menghadapi fakta kekurangan pemimpin di masa depan, sehingga pemimpin-pemimpin harus dihasilkan oleh seorang pemimpin melalui mentoring (Prihanto, 2018).

Memimpin di dalam gereja Tuhan pada dasarnya merupakan kasih karunia dan panggilan dari Allah sendiri, sehingga siapapun yang dipercayakan Allah untuk memimpin seharusnya tidak perlu dipertanyakan maupun dipersoalkan, seperti contoh ketika Tuhan katakan kepada Yeremia untuk tidak mempersoalkan tentang usianya yang masih muda ketika menerima panggilan dan utusan Tuhan (Yeremia:1:7-8), sebab Tuhan hendak memakai baik anak-anak muda maupun orang-orang yang lebih tua dalam penyertaan-Nya ajaib. Oleh karena itu, memimpin dalam gereja tidak ditentukan oleh usia, gelar, gender, kepintaran maupun senioritas, tetapi Tuhan hendak semua generasi dapat bersama-sama melayani pekerjaan-Nya. 
Pastor Tan Seow How yang adalah pemimpin dari gereja di Singapura Heart of God Church berkata bahwa kepemimpinan antargenerasi bukanlah pergantian tetapi penguatan atau bala bantuan (www.beritabethel.com, 12/11/2019). Dengan kata lain perlu ada perubahan pola pikir di dalam kepemimpinan gereja sehingga sungguh memperdayakan generasi muda dengan memperlakukan mereka sebagai pemimpin sejak saat ini dan bukan penonton. Kepemimpinan secara etis menuntut tanggung jawab dalam pencapaian visi dan misi, serta nilai-nilai yang ditemukan di dalam suatu organisasi. Selain itu menuntut juga tanggung jawab untuk mengkorelasikan tujuan organisasi dengan rekan-rekan dalam pekerjaan maupun pemangku kepentingan dari sisi eksternal (Candra \& Sundiman, 2020). Sebagai contoh, Yosua tidak menjadi pemimpin setelah kematian Musa yang adalah bapa rohaninya, tetapi sejak Musa masih memimpin, tanggung jawab sebagai pemimpin sudah dipercayakan kepadanya seperti memimpin peperangan (Keluaran 17:8-10), pengintai tanah Kanaan (Bilangan 13:16-20) atas perintah Tuhan. Hal itu memberi gambaran bahwa Tuhan sendiri hendak ada kerja sama antargenerasi dan bukan mengelompokkan generasi dalam kepemimpinan berdasarkan usia atau senioritas, sebab di zaman Yosua dipercayakan untuk melanjutkan kepemimpinan Israel, terdapat banyak orang lain yang lebih tua secara umur.

\section{B. Tidak Terdapat Interaksi Yang Ideal Antargenerasi}

Menurut (Anggraeni Lintang, 2020), kebersamaan dalam hidup berbagai angkatan generasi sering menjadi penyebab keadaan yang jauh dari kata damai oleh karena walaupun bersama, pada kenyataannya tidak saling kenal karena setiap orang ada di dalam perkumpulannya sesuai dengan kelompok masing-masing. Generasi muda kesulitan bersosialisasi dengan baik dengan generasi yang di atasnya dikarenakan terdapat ketidakseimbangan antara nilai yang ideal yang menjadi arahan angkatan yang lebih tua di banding realitas yang dihadapi mereka (Surya Yanuar Putra, 2017).

Beberapa skenario yang sering ditemukan dalam dinamika perubahan kepemimpinan berkaitan dengan relasi: Pertama, tipe gereja yang bergantung sepenuhnya pada seorang pemimpin, sehingga ketika yang bersangkutan meninggal dunia, gereja tidak siap dengan penggantinya. Kedua, pemimpin mempersiapkan pengantinya untuk memimpin setelah dirinya pensiun, dan itu yang disebut regenerasi. Ketiga, model gereja yang tim kepemimpinannya terdiri dan satu generasi yang berteman baik, sehingga berlaku sistem senioritas, karena dianggap generasi muda hadir hanya sebagai suruhan atau pelaksana perintah. Keempat, kepemimpinan yang diduduki oleh orang yang kurang kompeten dalam bidang yang dipercayakan sehingga tidak maksimal berfungsi sebagaimana semestinya. Menurut (Reddy \& Kamesh, 2016), kepemimpinan telah mengalami pergeseran dari fokus kepada aspek transformasional kepada suatu pengertian bahwa solusi atas pergumulan kepemimpinan terdapat di dalam relasi dan hubungan antara pemimpin dan orang-orang yang dipimpinnya. 
Kepemimpinan berbicara hubungan antara pemimpin dan orang-orang yang dipimpin. Yaitu orang-orang dengan berbagai karakteristik umur, jenis kelamin, kepribadian dan juga generasi sehingga sangat diperlukan dalam rangka meningkatkan efektivitas kepemimpinan gereja suatu tim yang terdiri dari berbagai karakteristik tadi sebagai representasi. Sebab kepemimpinan bersama juga berbicara tentang pikiran bersama dan bukan one man show yang menghasilkan pikiran tunggal. Kepemimpinan yang dilandasi pada karunia dan fungsi masing-masing dan bukan kepemimpinan yang didasarkan pada posisi semata. Diperlukan kepemimpinan antargenerasi untuk menggantikan kepemimpinan multigenerasi yang masih sering ditemukan di kalangan gereja. Menurut (Sriharmiati Leni, 2017) kepemimpinan akan lebih efektif apa bila berinteraksi dengan orang lain. Maka, (Harkness, 2012) menyatakan bahwa budaya persekutuan antargenerasi adalah sangat penting sehingga terbangun kebersamaan dan ikatan antarpribadi lintas generasi dimana iman dan praktik iman bersama dapat menjadi nyata. Orang menyukai kemudahan sehingga lebih memilih berhubungan dan berkomunikasi dengan orang yang sezaman dan sefrekuensi dari pada berusaha membangun budaya suatu komunitas kepemimpinan antargenerasi.

Cara hidup jemaat mula dapat menjadi rujukan, sebab mereka bertekun bukan sekedar dalam pengajaran, tetapi juga di dalam persekutuan, perkumpulan tanpa henti baik antara yang lebih tua umurnya dengan yang lebih muda, dan berdoa bersama (Kisah Para Rasul 2:41-42). Paulus sebagai contoh yang baik terus menerus berinteraksi dengan Timotius karena merindukan pertemuan-pertemuan dengannya, ingat akan dia sebagai anak didik dan kawan sepelayanan siang dan malam (2 Timotius 1:3-4). Yesus Kristus sendiri terus menerus membangun persekutuan dengan murid-murid-Nya dan mempercayakan kepada mereka tanggung jawab pelayanan bukan saja setelah dia naik ke surga, tetapi selama dia masih bersamasama dengan mereka melayani di bumi (Markus 3:13-19). Di dalam gereja mula, kepemimpinan terdiri dalam persekutuan di mana pemimpin terdiri dari ke-11 Rasul dan Matias yang bukanlah angkatan mereka dan yang telah dipilih untuk menggantikan posisi Yudas yang telah mati (Kisah Para Rasul 1:15-26). (Hahuluy, 2020) berkata bahwa Musa bukan memberi kepercayaan kepada Yosua dalam beberapa tugas, tetapi dia juga berusaha bentuk dan teguhkan iman Yosua kepada Allah. Dengan kata lain, Musa menjadi mentor bagi Yosua yang tentunya menunjukkan bahwa ia menyediakan waktu, pikiran, perasaan dan semua sarana yang bisa digunakan untuk mencapai tujuannya. Pelayanan antargenerasi menjadi suatu kebutuhan pada komunitas gereja, sebab itu merupakan kehendak Allah karena diperlukan untuk perkembangan pelayanan gerejawi dan misiNya, sehingga perlu mensosialisasi pemahaman kepemimpinan yang benar kepada semua kalangan di dalam jemaat dalam rangka meruntuhkan tembok-tembok pemisah yang sudah terpola dan justru menjadi hambatan bagi pelaksanaan pelayanan yang ideal seturut dengan kehendak Allah. Kepemimpinan antargenerasi merupakan wajah kekayaan 
dan keindahan gereja yang berdiri atas kasih Kristus yang menyatukan dan bukan memisahkan, yang membangun dan bukan menghancurkan.

\section{Kesimpulan}

Diperlukan pemahaman yang benar tentang kepemimpinan antargenerasi di dalam organisasi gereja agar kepemimpinan antargenerasi menjadi suatu budaya, sehingga bukan sekedar timbul kepercayaan, tetapi juga kerja sama antargerenasi dan bukan perpecahan. Sebab pemahaman kepemimpinan antargenerasi sebagai regenerasi atau giliran dan kurang interaksi antargenerasi menjadi ancaman bagi keberlangsungan gereja. Oleh karena itu, dibutuhkan interaksi yang baik antara generasi agar hubungan relasi yang erat dapat menjadi saluran menularkan pengetahuan baik dari yang lebih tua kepada yang lebih muda, maupun sebaliknya sehingga terjadi proses saling mengisi demi pencapaian tujuan ilahi. Sebab, tanpa interaksi antargenerasi, kemungkin kehilangan suatu atau berbagai generasi sangat terbuka. 


\section{BIBLIOGRAFI}

Adiawaty, Susi. (2019). Tantangan perusahaan mengelola perbedaan generasi karyawan. ESENSI: Jurnal Manajemen Bisnis, 22(3), 376-382. Google Scholar

Anggraeni Lintang. (2020). Gereja Kristen Jawa Purworejo Menjadi Gereja Intergenerasional. Tesis Universitas Kristen Duta Wacana Yogyakarta, 4.

Bencsik, Andrea, \& Machova, Renata. (2016). Knowledge sharing problems from the viewpoint of intergeneration management. ICMLG2016-4th International Conferenceon Management, Leadership and Governance: ICMLG2016, 42. Google Scholar

Bogdan, Robert C. (1992). Dan Steven J. Taylor. Introduction to Qualitative Research Methotds: A Phenomenological Approach in the Social Sciences, Alih Bahasa Arief Furchan, John Wiley Dan Sons. Google Scholar

Candra, Willy, \& Sundiman, Didi. (2020). Sustainable Leadership Key Factors: Study On Profit And Non Profit Organisations In Batam Indonesia. Jurnal Manajemen Dan Kewirausahaan (Journal of Management and Entrepreneurship), 22(2), 122130. Google Scholar

Douglas, Scott Michael. (2013). Intergenerational Discipleship for Leadership Development: A Mixed-Methods Study. Southern Baptist Theological Seminary. Google Scholar

Hahuluy, Michael Salomo. (2020). Menerapkan Pola Regenerasi Kepemimpinan Musa kepada Yosua. Jurnal Teologi Gracia Deo, 3(1), 24-41. Google Scholar

Harkness, Allan G. (2012). Intergenerationality: Biblical and theological foundations. Christian Education Journal, 9(1), 121-134. Google Scholar

Julita Nafthalia Leander. (2019). Rancang Bangun Gereja Intergenerasional di Gereja Kristen Protestan di Bali Jemaat Hosana Kwanji. Tesis Universitas Kristen Duta Wacana Yogyakarta, 6.

Kassi Henos, Ervi Johan Lo, Sabar Manahan Hutagalung, David Martinus Gulo. (2018). Peran Gereja Dalam Regenerasi Pemimpin Rohani, Real Didache. Jurnal Teologi Dan Pendidikan Agama Kristen, 3(2), 30-36.

Norrod, Benjamin. (2020). Intergenerational Disunity in Nondenominational Tennessee Pentecostal Churches: An Intrinsic Multiple Case Study. University of Phoenix. Google Scholar

Prihanto, Agus. (2018). Peran Proses Mentoring Pemimpin Kaum Muda Bagi Perkembangan Pelayanan Pemuda Di Gereja. Jurnal Jaffray, 16(2), 197-212. Google Scholar

Reddy, Asi Vasudeva, \& Kamesh, A. V. S. (2016). Integrating servant leadership and 
ethical leadership. In Ethical leadership (pp. 107-124). Springer. Google Scholar

Schlesman, Shane Glen. (2020). The Passing Zone: Building an Intergenerational Leadership Team. Assemblies of God Theological Seminary. Google Scholar

Sriharmiati Leni. (2017). Relasi Kepemimpinan dan Komunikasi Dengan Motivasi Kerja di DKI Jakarta. Jurnal Mahasiswa Administrasi Negara (IMAN), 1(1), 21-29.

Surya Yanuar Putra. (2017). Theoritical Review: Teori Perbedaan Generasi. Among Makarti, 9(2), 123-134. Google Scholar

\section{Copyright holder:}

Djone Georges Nicolas (2021)

First publication right:

Journal Syntax Literate

This article is licensed under:

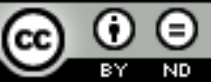

